Sharif University of Technology
Scientia Iranica
Transactions E: Industrial Engineering
SCIENTIA
I RAN I C A

\title{
Optimizing supply chain network design with location-inventory decisions for perishable items: A Pareto-based MOEA approach
}

\author{
S. Rashidi ${ }^{a}$, A. Saghaei ${ }^{a, *}$, S.J. Sadjadi ${ }^{b}$ and S. Sadi-Nezhad ${ }^{a}$ \\ a. Department of Industrial Engineering, Science and Research Branch, Islamic Azad University, Tehran, Iran. \\ b. Department of Industrial Engineering, Iran University of Science and Technology, Narmak, Tehran, Iran. \\ Received 10 February 2015; received in revised form 30 September 2015; accepted 8 December 2015
}

\author{
KEYWORDS \\ Supply chain network \\ design; \\ Perishable products; \\ Location-inventory; \\ Multi-objective \\ optimization; \\ Pareto-based \\ meta-heuristics.
}

\begin{abstract}
In this paper, a bi-objective mathematical model is presented to optimize supply chain network with location-inventory decisions for perishable items. The goal is to minimize total cost of the system, including transportation cost of perishable items from hub center into DCs and from DCs to ultimate centers, transportation cost of unusual orders, and fixed cost of centers as DCs, as well as demand unresponsiveness. Considering special conditions for holding items and regional DCs, and determining average lifetime for the items assigned to centers are other features of the proposed model. With regard to complexity of the proposed model, a Pareto-based meta-heuristic approach, called Multi-Objective Imperialist Competitive Algorithm (MOICA), is presented to solve it. To demonstrate performance of the proposed algorithms, two well-developed multiobjective algorithms based on genetic algorithm, including Non-dominated Ranked Genetic Algorithm (NRGA) and Non-dominated Sorting Genetic Algorithm (NSGA-II), are applied. In order to analyze the results, several numerical illustrations are generated; then, the algorithms are compared both statistically and graphically. Analysis of the results shows the robustness of MOICA to find and manage Pareto solutions.

(C) 2016 Sharif University of Technology. All rights reserved.
\end{abstract}

\section{Introduction}

Promptly changing environment makes the corporations to accommodate themselves with the whole supply chain. Supply Chain Network Design (SCND) problems have been attended as an important issue in market globalization. The problem of SCND involves determining a flow pattern for each product with strategic and operational decisions, including facilities location and inventory management, to be closer to reality and follow some goals such as total cost, customer satisfaction, chain risk, etc. [1]. Service supply chains are usually complicated to manage, especially

\footnotetext{
*. Corresponding author. Tel./Fax: +982122025487 E-mail address: abbas.saghaei (A. Saghaei)
}

when they concern perishable products with a very high service level [2].

Numerous products are in the category of perishable items; e.g. radioactive elements, blood banks, chemicals products, food, fashion clothes, technical components, and newspapers [3-5]. The operations research community began studying the deterioration of items by modeling inventory management in blood banks [6-7] and the distribution of blood from transfusion centers to hospitals [8-9]. For more details on blood products in Supply Chain Management (SCM), one can refer to $[10,11]$.

The supply chain of perishable products mostly concentrates on improved communication among the supply chain players, and well-coordinated and fast distribution channels. These facts lead to increase in 
profit and, consequently, achieving reduction in cost. The shelf life limitation, overproduction, and storage are the main features in the literature on perishable products [12]. These problems also deal with stockouts, outdates, and discarding cost, and, in most cases, customer returns are not accepted or realistically possible. Carter and Rogers [13] investigated related works with a conceptual framework for sustainable supply chains. Nagurney and $\mathrm{Yu}$ [14] developed a new model of oligopolistic competition for fashion supply chains with differentiated products, including environmental concerns. Büyüközkan and Berkol [15] proposed a methodology for designing a sustainable supply chain by using an integrated analytic network process and zero-one goal programming approach in quality function deployment. Chaabane et al. [16] investigated the design of sustainable supply chains under emissions trading schemes. Erol et al. [17] proposed a fuzzy multi-criteria framework to evaluate and measure sustainability performance of a supply chain in Turkish grocery retailers.

Perishable products are increasingly important to customers who desire to reduce the amount of outdated perishable products. Perishable products start deteriorating the moment they are produced [18]. Consideration of perishability in the supply chain has received increased attention in recent research [19]. Govindan et al. [20] presented a model by integrating sustainability in decision making for distribution in a perishable food supply chain network. With globalization of supply chains, the distance between nodes in the distribution network has considerably increased. Katsaliaki et al. [21] concentrated on the blood supply chain game, which simulated the supply chain of blood units from donors to patients based on a real case study by modeling the UK blood supply chain. Duan and Liao [22] presented a combinational approach to optimize efficiency of the supply chain system for a single-hospital singleblood center. Kalaitzidou et al. [23] introduced a general mathematical programming framework, which employed an innovative generalized supply chain network composition joined with forward and reverse logistics activities. Fattahi et al. [24] presented a problem formulation for planning a multi-echelon and multi-product supply chain network over a multiperiod horizon in which customer zones followed pricesensitive demands. Mousazadeh et al. [25] proposed a bi-objective mixed integer linear programming model for a pharmaceutical supply chain network design problem. Govindan et al. [26] covered this gap by considering the sustainable OAP in the sustainable SCND as a strategic decision. Sharifzadeh et al. [27] proposed an SCND, where systematic decision-making for centralized, distributed, and mobile biofuel production was used by using mixed integer linear program- ming under uncertainty. Ahn et al. [28] developed a deterministic mathematical programming problem for strategic planning design of a Microalgae Biomassto-Biodiesel Supply Chain Network (MBBSCN) from feedstock fields to end users that met resource, demand, and technology constraints over a long-term period. Pop et al. [29] proposed an efficient reverse distribution system for solving sustainable supply chain network design problem and discussed the results using a realworld case study. Yolmeh and Salehi [30] proposed an outer approximation method for integration of supply chain network designing and assembly line balancing under uncertainty.

In the recent years, multi-objective optimization has received increased attention in operational and industrial applications. Soft-computing approaches are one of the best developed approaches to deal with optimization of the systems. Among multi-objective optimization algorithms, Non-dominated Sorting Genetic Algorithm (NSGA-II) is a commonly used Paretobased algorithm proposed by Deb et al. [31]. This algorithm is applied in different aspects of industrial and operational management [32-33]. Atashpaz-Gargari and Lucas [34] presented a new kind of evolutionary algorithm, called Imperialist Competitive Algorithm (ICA), which was inspired by a social phenomenon. They used this algorithm for some benchmark problems to show its ability in finding good solution. Yang et al. [35] proposed a multi-objective biogeography-based optimization for supply chain network design under uncertainty.

In this paper, a bi-objective mathematical programming model is presented to optimize supply chain network with location-inventory decisions for perishable items. The goals are to minimize whole cost of the system, including transportation cost of perishable items from hub center to DCs and from DCs to the ultimate center, transportation cost of unusual orders, and fixed cost of centers as DCs, as well as demand unresponsiveness. Considering special conditions for holding items and regional DCs, and determining average lifetime of items assigned to centers are other features of the proposed model. With regard to complexity of the proposed model, a Pareto-based multi-objective approach, called Multi-Objective ICA (MOICA), is presented to optimize the mathematical model. To compare the performance of ICA, bestdeveloped Pareto-based genetic algorithms are applied.

The rest of this paper is organized as follows; in Section 2, the parameters and variables are defined and, then, the bi-objective model is formulated. In Section 3, the multi-objective Pareto-based meta-heuristic algorithms are explained. Next, the results and comparisons are analyzed in Section 4. Finally, the conclusions and further research are given . 


\section{Model description}

In this section, the problem of three-echelon supply chain network design is presented. In this supply chain, a hub center produces or provides perishable items. In the second echelon, regional DCs investigate specific operational regions. Finally, in the last echelon, service centers are present to directly connect with the customers. The physical flow of perishable items occurs from different centers to customers. In this situation, different questions should be answered, simultaneously, as follows:

- Which center should be selected as the DC among all the centers in a region?

- What kind of perishable items the ultimate centers must be able to accept?

- How much of each perishable item must be allocated to each center?

- How long is optimal life of perishable items?

Another feature of the problem is inventory management at two levels of DCs and ultimate centers. Parts of inventory assigned to them consist of onhand inventory and safety stock based on $(S-1, S)$ inventory review policy. In the problem structure, when the on-hand inventory reaches the safety stock, the order of the next period is opened. If demand is greater than on-hand inventory, in addition to order of the next period, a special order is sent to cover most of the demands. Furthermore, considering special conditions for holding items and regional DCs, and determining average lifetime for the items assigned to centers are other features of the proposed model. Figure 1 represents the corresponding supply chain network design, schematically.

This paper formulates the abovementioned supply chain network with location-inventory decisions for perishable items as a bi-objective model, in which the first objective function attempts to minimize demand unresponsiveness. The second objective function tries to minimize total cost, including transportation cost of perishable items from centers to DCs and from DCs to the ultimate center, transportation cost of unusual orders, and fixed cost of centers as DCs. As well, panning horizon is single-period and demands are known with a constant rate. In the following subsections, notations, decision variables, and mathematical formulation of the problem are described.

\subsection{Indices and parameters}

$i \quad$ Index of perishable items

j Index of service centers

$l \quad$ Index of geographical region

$k \quad$ Index of candidate site

$f \quad$ Index of second-service centers
$T \quad$ Number of the period (e.g., number of days in each problem number)

$D_{i, k} \quad$ Demand quantity of item $i$ at candidate site $k$

$C S_{i, k} \quad$ Demand unresponsiveness cost for item $i$ in candidate site $k$

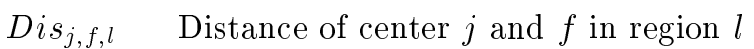

$D i s_{j, k} \quad$ Distance of center $j$ from candidate site $k$

$S S_{i, j} \quad$ Safety stock for item $i$ in center $j$

$D i_{j} \quad$ Distance of center $j$ from hub center

$I C_{j} \quad$ Fixed cost of center $j$ for being hub

$s_{i, j} \quad$ Unusual order batch item $i$ assigned to center $j$

$A D \quad$ Maximum allowable distance for providing service

CT Fixed shipping cost of items for DCs

Ctr Shipping cost of items from DCs to ultimate centers

$M \quad$ A large number

$C F_{i} \quad$ Consumption coefficient of item $i$

$L T_{i, j} \quad$ Average life of item $i$ assigned to center $j$

\subsection{Decision variables}

$Z_{j, l} \quad 1$ if center $j$ is selected as hub center in region $l$ and 0 otherwise

att $_{i, j} \quad 1$ if item $i$ can be provided in center $j$ and 0 otherwise

$R e_{i, j, k} \quad 1$ if item $i$ from center $j$ assigned to candidate site $k$ (ultimate center) and 0 otherwise

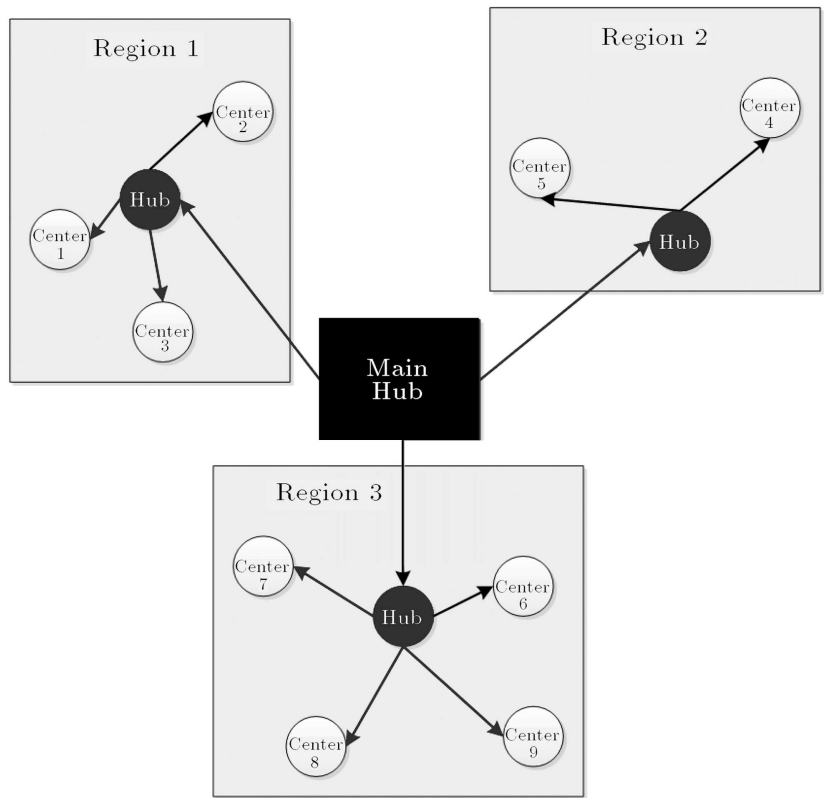

Figure 1. Scheme of the corresponding supply chain network design. 


\section{$y_{i, j} \quad 1$ if unusual order for item $i$ is opened in center $j$ and 0 otherwise \\ $Q_{j, f} \quad 1$ if distance of two centers is less than the allowable level and 0 otherwise \\ $U_{j, k} \quad 1$ if distance of candidate site $k$ from center $j$ is less than the allowable level and 0 otherwise \\ $E_{i, j} \quad 1$ if the assigned inventory level meets the demand in the period and 0 otherwise \\ $V_{i, j} \quad 1$ if item $i$ assigned to center $j$ lives less than one period and 0 otherwise \\ $W_{i, k} \quad 1$ if demand of item $i$ assigned to site $k$ is less than one period and 0 otherwise \\ $\eta_{i, j} \quad$ Quantity of item $i$ assigned to center $j$ \\ $A m_{i, j, k} \quad$ Quantity of item $i$ assigned from center $j$ to candidate site $k$ \\ $I L_{i, j} \quad$ Inventory level of item $i$ in center $j$ at beginning of the period \\ Demand $_{i, j} \quad$ Total demand of different regions on item $i$ for the center $j$}

\subsection{Bi-objective model}

$$
\begin{aligned}
\operatorname{Minimize} & \sum_{i} \sum_{k} C S_{i, k}\left|D_{i, k}-\sum_{j} A m_{i, j, k}\right|, \\
\text { Minimize } & C T \sum_{i} \sum_{j} \sum_{l} D i_{j} \eta_{i, j} Z_{j, l} \\
& +C t r \sum_{i} \sum_{j} \sum_{k} A m_{i, j, k} D S_{j, k} \\
& +\sum_{i} \sum_{j} S_{i, j} y_{i, j} E_{i, j}+\sum_{j} \sum_{l} Z_{j, l} I C_{j},
\end{aligned}
$$

s.t.

$$
\begin{aligned}
& \sum_{j} Z_{j, l} \geq 1 \\
& \sum_{i} \sum_{j} a t t_{i, j} Z_{j, l} \geq 1 \\
& R e_{i, j, k}=a t t_{i, j} U_{j, k} \\
& \eta_{i, j}\left(1-\sum_{l} Z_{j, l}\right) \\
& \quad=\left(1-\sum_{l} Z_{j, l}\right) \sum_{k} \sum_{f} \operatorname{Re}_{i, f, k} A m_{i, f, k}, \\
& \eta_{i, j} \sum_{l} Z_{j, l}=\sum_{f} Q_{j, f} A m_{i, j, f} \sum_{l} Z_{j, l}, \\
& D i s_{j, f, l}<A D+M\left(1-Q_{j, f}\right),
\end{aligned}
$$

$$
\begin{aligned}
& D i s_{j, f, l} \geq A D-M Q_{j, f}, \\
& Z_{j, l}+Q_{j, f} \geq Z_{j, l} Q_{j, f}+1, \\
& D s_{j, k}<A D+M\left(1-U_{j, k}\right), \\
& D s_{j, k} \geq A D-M U_{j, k}, \\
& \operatorname{Demand}_{i, j}=\sum_{k} R e_{i, j, k} D_{i, k}, \\
& L T_{i, j} a t t_{i, j}<T+M\left(1-V_{i, j}\right), \\
& L T_{i, j} a t t_{i, j} \geq T-M V_{i, j}, \\
& \left\lfloor\frac{D_{i, k}}{C F_{i}}\right\rfloor<T+M\left(1-w_{i, k}\right), \\
& \left\lfloor\frac{D_{i, k}}{C F_{i}}\right\rfloor \geq T-M w_{i, k}, \\
& \sum_{k}\left(T-\left\lfloor\frac{D_{i, k}}{C F_{i}}\right\rfloor\right) C F_{i} w_{i, k}<\sum_{k}\left(I L_{i, j}+A m_{i, j, k}\right) \\
& \quad y_{i, j} \\
& \quad+M\left(1-E_{i, j}\right), \\
& I L_{i, j}+\eta_{i, j}<S S_{i, j}+M\left(1-y_{i, j}\right), \\
& A L_{i, j}+\eta_{i, j} \geq S S_{i, j}-M y_{i, j}, \\
& \sum_{k} \leq \operatorname{demand}_{i, j} R e_{i, j, k}, \\
& \quad A m_{i, j, k}^{l t}=A m_{i, j, k}, \\
& \quad\left(T-\left\lfloor\frac{D_{i, k}}{C F_{i}}\right\rfloor\right) C F_{i} w_{i, k} \geq \sum_{k}\left(I L_{i, j}+A m_{i, j, k}\right) \\
& y_{i, j}, I L_{i, j}, L T_{i, j}, \eta_{i, j} \in Z
\end{aligned}
$$

Objective (1) minimizes demand unresponsiveness. Objective (2) minimizes total cost, including transportation cost of perishable items from hub center to DCs and from DCs to the ultimate center, transportation cost of unusual orders, and fixed cost of centers as DCs. Constraint (3) ensures that one of the centers is selected as hub center in regions. Constraint (4) assures that all items exist and are distributable. Constraint (5) ensures the way of providing service to items in regions. Constraints (6) and (7) investigate the assigned amount to centers and hubs. Constraints (8) and (9) ensure an upper bound for the distance between 
hub center and the ultimate center. Constraint (10) measures the distance between hub centers with other ones. Constraints (11) and (12) ensure an upper bound for the distance between demand nodes and the ultimate center. Constraint (13) considers whole demand of a region for each item. Constraints (14) and (15) show if the lifetime of item $i$ in center $j$ is less than current period. Constraints (16) and (17) are also dependently seeking to determine whether the consumption of items in the current inventory lasts more than the current time period or not. Constraints (18) and (19) provide the inventory policy of the system. Constraints (20) and (21) measure the unusual orders. Constraint (22) ensures that the assigned items to each region are less than or equal to the demand in the region. Constraint (23) shows summation of item $i$ is fulfilled by center $j$ for ultimate center $k$ during different lifes. Constraint (24) provides the range of decision variables.

\section{Solving methodologies}

Many researchers have successfully applied metaheuristic approaches to solve complicated optimizations in different fields of industrial and operation management. These researchers have also involved the NP-hard mixed binary integer programming for supply chain network design problem [13-15]. In this section, the recently developed Pareto-based metaheuristic algorithms, called MOICA, NSGA-II, and NRGA, are proposed to solve the proposed bi-objective mathematical formulation at hand. However, some required multi-objective backgrounds are first defined in the following subsection.

\subsection{Concepts of multi-objective algorithms}

Consider a multi-objective model with a set of conflict objectives, $f(\vec{x})=\left[f_{1}(\vec{x}), \ldots, f_{m}(\vec{x})\right]$, subject to $g_{i}(\vec{x}) \leq$ $0, i=1,2, \ldots, c, \vec{x} \in X$, where $\vec{x}$ denotes $n$-dimensional vectors that can get real, integer, or even Boolean values and $X$ is the feasible region. Then, for a minimization model, solution $\vec{a}$ dominates solution $\vec{b}(\vec{a}, \vec{b} \in X)$ if $f_{i}(\vec{a}) \leq f_{i}(\vec{b}), \forall i=1,2, \ldots, m$ and $\exists i \in\{1,2, \ldots, m\}: f_{i}(\vec{a})<f_{i}(\vec{b})$.

Pareto-based algorithms aim to achieve the Pareto optimal front during the evolution process. This front is expected to have the highest convergence and diversity [31].

\subsection{Solution representation}

To code the solutions, the continuous decision variables are encoded and randomly generated between zero and their upper bounds. Following this, to encode and decode the binary decision variables, a continuous random keys representation is applied. For more details, one can refer to Rahmati et al. [36]. In other words, most of the constraints of the model are satisfied through the proposed vector and the rest of the violating constraints will be penalized. Since some constraints are likely to be violated, they are penalized using the method given in Yeniay and Ankare [37]. In other words, infeasible solutions are fined using Eq. (25):

$$
P(x)=M \times\left[\left(\frac{g(x)}{b}\right)-1 \geq 0\right],
$$

where $M, g(x)$, and $P(x)$ represent a large number, the constraint under consideration, and the penalty value, respectively. This equation is designed for a constraint like $g(x) \leq b$ and more violations receive bigger penalties.

\subsection{Multi-Objective Imperialist Competitive Algorithm (MOICA)}

Imperialist Competitive Algorithm is a kind of Evolutionary Algorithms proposed by Atashpaz-Gargari and Lucas [34] for the first time. This algorithm searches the solution space by using some initialized countries. Competition among imperialists and their attempts to affect their colony states are inspired as a source in ICA.

Over the past years, ICA has been used as a meta-heuristic approach for a wide range of singleobjective problems. Its capability in finding nearoptimal solutions for different single objectives makes it proper for multi-objective problems. Enayatifar et al. [38] developed an EV based on ICA for a multiobjective problem, called Multi-Objective Imperialist Competitive Algorithm (MOICA), and tested this algorithm on six well-known test functions.

In this paper, an MOICA, as another metaheuristic approach, is used to solve the presented inventory model and compare the results with other approaches. The steps of the proposed MOICA can be described as follows:

1. Initializing the empires by creating $N_{\text {pop }}$ countries, selecting $N_{i m p}$ of the most powerful countries as imperialists and the remaining countries as colonies $\left(N_{c o l}\right)$, and giving N.C $C_{n}$ colonies to each imperialist by using Eq. (27).

Power of each country is determined based on two criteria: the rank of each country, which is calculated by using non-dominated sorting with regard to all objective functions, and merit of countries with the same rank. According to the mentioned criteria, the power of each country can be computed by using Eq. (26) [38]:

$$
\begin{aligned}
& \operatorname{power}_{n}= \\
& \sum_{j=1}^{D}\left[f_{i}(C) / \sum_{i=1}^{N_{\text {rank }}(C)} f_{i}(i)\right](\operatorname{Rank}(C)-1) \times D^{(26)}
\end{aligned}
$$




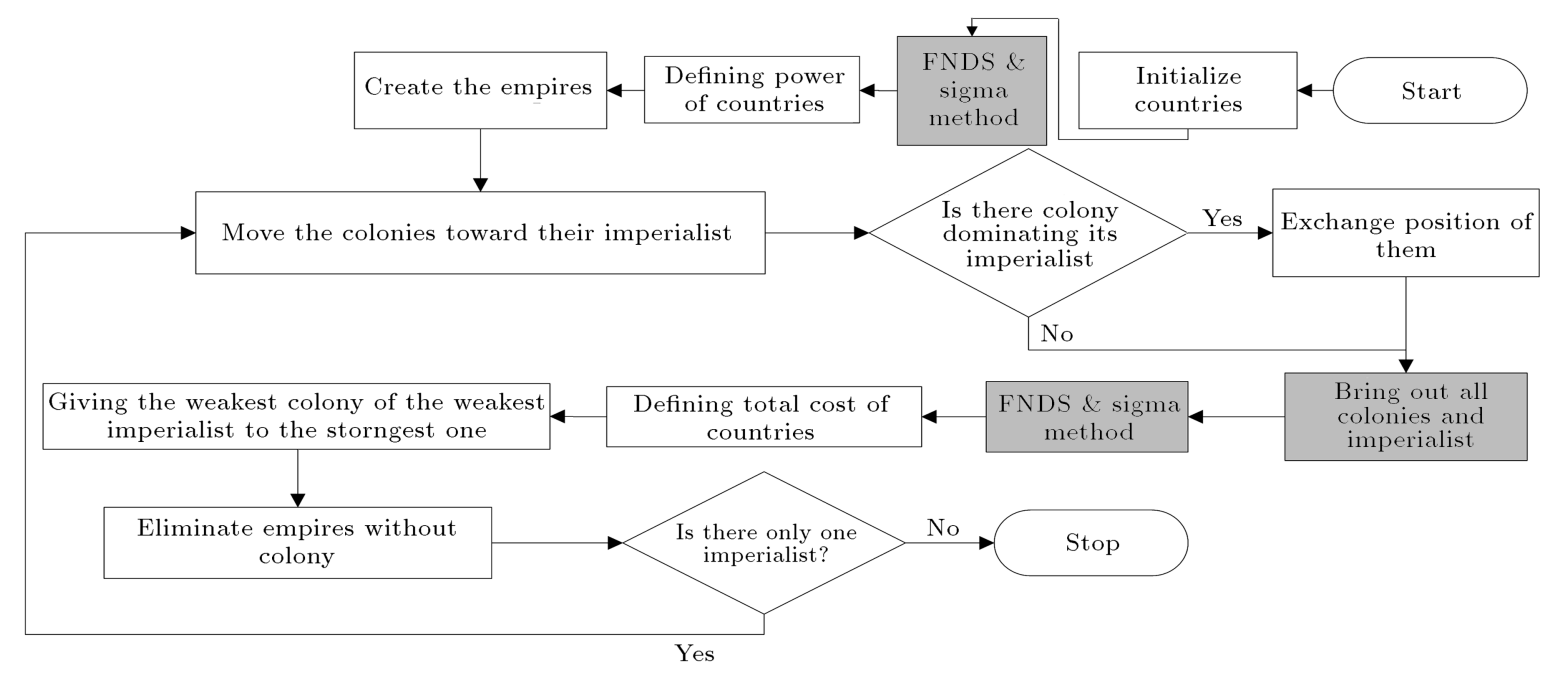

Figure 2. The flowchart of MOICA.

where $D$ is the number of objective functions, $f(i)$ is value of the $i$ th objective function, and $N_{\text {rank }}(C)$ is the number of countries in rank $C$ :

$$
N C_{n}=\operatorname{round}\left\{p_{n} N_{c o l}\right\}
$$

where $p_{n}=\left|\frac{\text { power }_{n}}{\sum_{i=1}^{N_{\text {imp }} \text { power }_{i}}}\right|$.

2. Moving the colonies toward their imperialists according to a random variable of uniform distribution with regard to the distance between each colony and its imperialist (Eq. (28)) and considering a deviation in the movement (Eq. (29)):

$$
\begin{aligned}
& x \sim U(0, \beta \times d), \\
& \theta \sim U(-\gamma, \gamma) .
\end{aligned}
$$

3. Exchanging position of imperialist and colony by computing the fitness function of each colony after moving and choosing the best member of empire (the member with the best fitness function) among imperialists and moved colonies as a new imperialist;

4. Computing the total cost of all empires by determining the total cost of each imperialist with regard to its own position and the mean of its colonies' positions (Eq. (30)):

$$
\begin{aligned}
T C_{n}= & \operatorname{Cost}\left(\text { imperialist }_{n}\right) \\
& +\zeta \text { mean }\{\text { cost } t(\text { colonies })\},
\end{aligned}
$$

where $\zeta$ is a positive number less than 1 that indicates the influence of mean cost of colonies on the imperialist cost;

5. Imperialist competition by giving the weakest colony of the weakest imperialist to the strongest one with regard to the normalized total cost is carried out (Eq. (31)):

$$
N T C_{n}=T C_{n}-\max \left\{T C_{n}\right\} .
$$

6. Eliminating the powerless empires by omitting the imperialist which has lost all its colonies.

The flowchart of the proposed MOICA is shown in Figure 2 in which the multi-objective parts are highlighted.

\subsection{NSGA-II and NRGA algorithms}

One of the popular non-domination based evolutionary algorithms for multi-objective problems is Nondominated Sorting Genetic Algorithm (NSGA), which was proposed by Srinivas and Deb [39]. Like other evolutionary algorithms, this approach works with a population of solutions to find the optimum solution in the space. With regard to the main criticisms of this algorithm, such as complexity of non-dominated sorting and lack of elitism, NSGA-II, as a modified version of this algorithm, was proposed by Deb et al. [31]. Another popular extension of evolutionary algorithms is Non-dominated Ranked Genetic Algorithm (NRGA), which is widely used for multi-objective problems. For more details about NSGA-II and NRGA, one can refer to $[33,36,40]$.

In this paper, both NRGA and NSGA-II algorithms, which are GA based and use the evolution process of genetic algorithm, are used. The parameters of both NRGA and NSGA-II algorithms, such as population size, are determined identically. The mutation processes for both algorithms are the same. Their crossover operator is defined based on Haupt, R.L. and Haupt, S.E. [41] uniform crossover operator. Besides, there is a difference between them in their selection strategies. In fact, the proposed NSGA-II uses a binary tournament selection while a Rolette wheel selection strategy is used in NRGA. Figure 3 shows the 


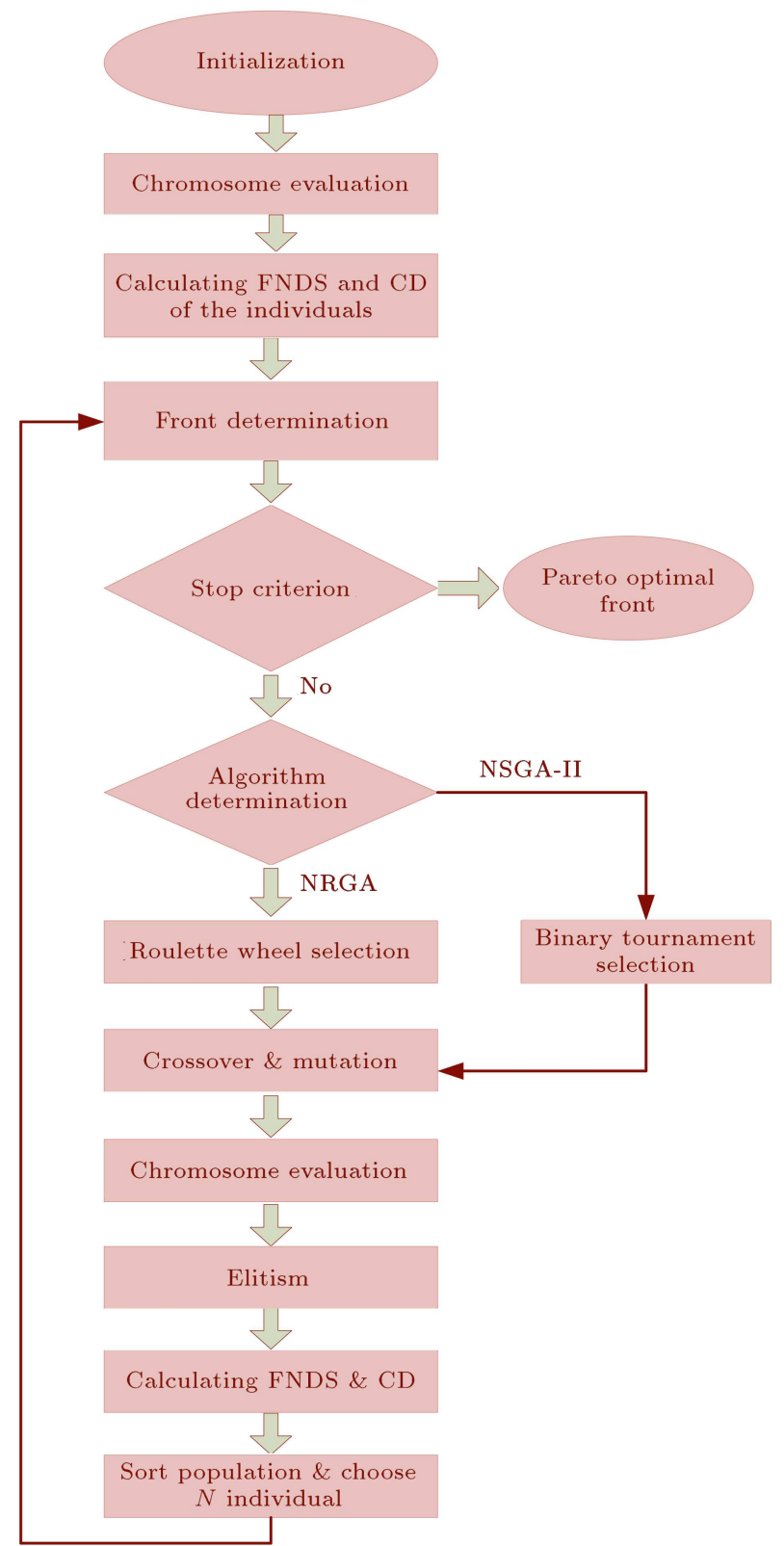

Figure 3. The flowchart of NSGA-II and NRGA.

flowchart of both NRGA and NSGA-II algorithms in which the multi-objective parts are highlighted.

\section{Analysis of results and comparisons}

To evaluate performances of the proposed Pareto-based algorithms, four standard metrics of multi-objective algorithms are spacing that measures the standard deviation of the distances among solutions of the Pareto front, in which smaller value is better [42]; Mean Ideal Distance (MID) [43]; Number Of found Solutions (NOS) that counts the number of the Pareto solutions in Pareto optimal front, in which bigger value is better; and computational (CPU) time of running the algorithms to reach near-optimum solutions.
Table 1. Values of the parameters of the algorithms.

\begin{tabular}{ccc}
\hline $\begin{array}{c}\text { Multi-objective } \\
\text { algorithms }\end{array}$ & $\begin{array}{c}\text { Algorithm } \\
\text { parameters }\end{array}$ & $\begin{array}{c}\text { Optimum } \\
\text { amount }\end{array}$ \\
\hline & $\begin{array}{c}\text { Number of population } \\
\text { Number of imperialists }\end{array}$ & 40 \\
MOICA & A random variable & 2 \\
& $\begin{array}{c}\text { Deviation form original } \\
\text { direction }\end{array}$ & 0.6 \\
& Influence coefficient of & 0.1 \\
& colonies & 100 \\
& Maximum generation \\
& Number of population & 25 \\
NRGA \& & Crossover probability & 0.6 \\
NSGA-II & Mutation probability & 0.4 \\
& Maximum number of & 100 \\
& generations & \\
\hline
\end{tabular}

Table 2. Input parameters of the model for the generated test problems.

\begin{tabular}{ccccc}
\hline $\begin{array}{c}\text { Problem } \\
\text { no. }\end{array}$ & Item & Center & Region & $\begin{array}{c}\text { Candidate } \\
\text { site }\end{array}$ \\
\hline 1 & 10 & 5 & 2 & 5 \\
2 & 20 & 5 & 2 & 5 \\
3 & 50 & 15 & 2 & 10 \\
4 & 50 & 20 & 3 & 10 \\
5 & 85 & 45 & 3 & 20 \\
6 & 100 & 75 & 3 & 40 \\
7 & 135 & 95 & 5 & 50 \\
8 & 165 & 110 & 5 & 70 \\
9 & 220 & 145 & 5 & 120 \\
10 & 310 & 175 & 10 & 140 \\
11 & 450 & 220 & 10 & 160 \\
12 & 800 & 550 & 20 & 250 \\
\hline
\end{tabular}

The experiments are implemented on 12 test problems. Furthermore, to eliminate uncertainties of the obtained solutions, each problem is used three times under different random environments. Then, the averages of these three runs are treated as the ultimate responses. The NSGA-II, as the most applicable Pareto-based MOEA in the literature, is applied to demonstrate capability of the proposed algorithms to solve the multi-objective optimization problems. The input parameters of the algorithms are reported in Table 1.

To evaluate the performance of the proposed algorithms, Table 2 shows input parameters of the model for the generated test problems, and Table 3 reports amounts of the multi-objective metrics for the 12 test problems. MATLAB Software [44] has been 
Table 3. Multi-objective metrics computed for the three proposed Pareto-based meta-heuristics.

\begin{tabular}{|c|c|c|c|c|c|c|c|c|c|c|c|c|}
\hline \multirow{2}{*}{$\begin{array}{c}\text { Problem } \\
\text { no. }\end{array}$} & \multicolumn{4}{|c|}{ MOICA } & \multicolumn{4}{|c|}{ NSGA-II } & \multicolumn{4}{|c|}{ NRGA } \\
\hline & NOS & MID & Spacing & Time & NOS & MID & Spacing & Time & NOS & MID & Spacing & Time \\
\hline 1 & 12 & 3243 & 46333 & 13.52 & 24 & 4373 & 57838 & 22.66 & 21 & 4987 & 64747 & 25.03 \\
\hline 2 & 14 & 4352 & 52532 & 19.14 & 21 & 6783 & 89388 & 33.91 & 19 & 7763 & 98489 & 29.63 \\
\hline 3 & 14 & 4334 & 97493 & 23.51 & 22 & 19734 & 78377 & 36.88 & 19 & 9827 & 63734 & 34.74 \\
\hline 4 & 12 & 23782 & 13442 & 34.53 & 21 & 75839 & 73833 & 41.10 & 21 & 47839 & 83734 & 51.11 \\
\hline 5 & 15 & 34884 & 93004 & 44.73 & 23 & 67839 & 89101 & 61.62 & 21 & 87363 & 98441 & 78.61 \\
\hline 6 & 10 & 32499 & 453831 & 67.02 & 23 & 87322 & 349391 & 94.01 & 22 & 67827 & 176061 & 89.11 \\
\hline 7 & 9 & 67283 & 768501 & 75.14 & 19 & 118927 & 984777 & 119.15 & 23 & 96771 & 388310 & 109.82 \\
\hline 8 & 12 & 367983 & 878851 & 89.16 & 19 & 487328 & 837831 & 169.75 & 23 & 578483 & 787001 & 148.21 \\
\hline 9 & 9 & 359993 & 873031 & 90.08 & 21 & 862788 & 1481188 & 128.83 & 18 & 983461 & 234993 & 174.23 \\
\hline 10 & 9 & 984398 & 2377301 & 123.19 & 21 & 1097711 & 1938478 & 198.70 & 19 & 2388201 & 1288731 & 241.44 \\
\hline 11 & 8 & 384995 & 3397591 & 234.71 & 20 & 1288738 & 3099312 & 291.63 & 19 & 1172600 & 3488841 & 248.42 \\
\hline 12 & 9 & 1387389 & 4918991 & 310.85 & 21 & 3460021 & 4909941 & 433.27 & 18 & 3672882 & 5191021 & 398.69 \\
\hline
\end{tabular}

Table 4. The P-values of the analysis of variance comparison test.

\begin{tabular}{ccl}
\hline Metric & P-value & \multicolumn{1}{c}{ Test results } \\
\hline MID & 0.470 & Null hypothesis is not rejected \\
Spacing & 0.956 & Null hypothesis is not rejected \\
NOS & 0.000 & Null hypothesis is rejected \\
Time & 0.564 & Null hypothesis is not rejected \\
\hline
\end{tabular}

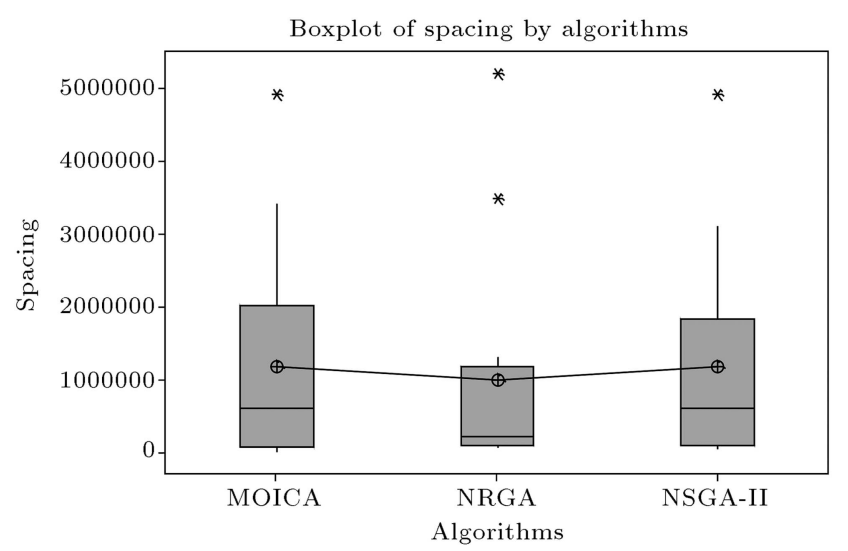

Figure 4. Box plot of spacing vs. algorithms.

used to code the proposed meta-heuristic algorithms, and the programs have been executed on a $2-\mathrm{GHz}$ laptop with $4 \mathrm{~GB}$ of RAM.

The algorithms are statistically compared based on the properties of their obtained solutions via the analysis of variance (ANOVA) test. These outputs are reported in Table 4 in terms of defined metrics. In order to clarify our statistical results, individual value plots are represented in Figures 4-7. Figure 8 also represents the graphical compa- rison of these three algorithms.

The result based on the statistical outputs in Table 3 along with Figures 4-7 shows the comparability of MOICA in comparison with NRGA and NSGAII in

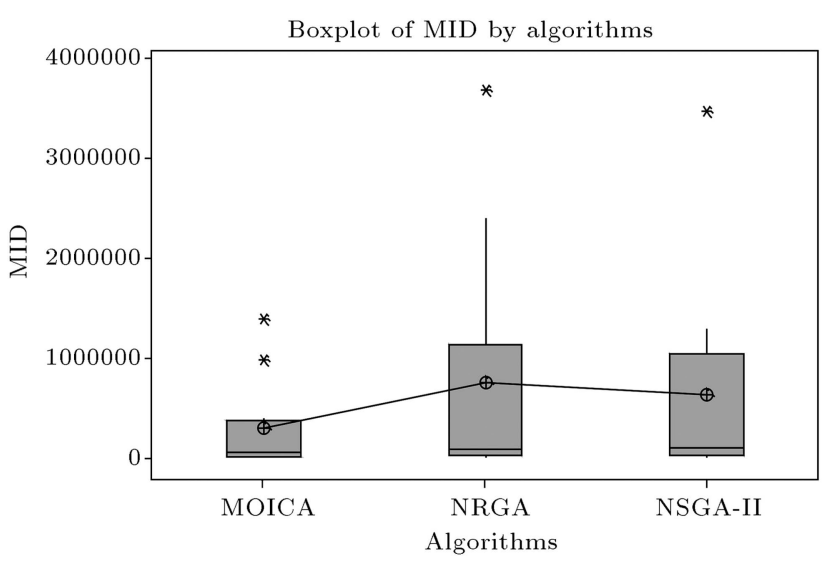

Figure 5. Box plot of MID vs. algorithms.

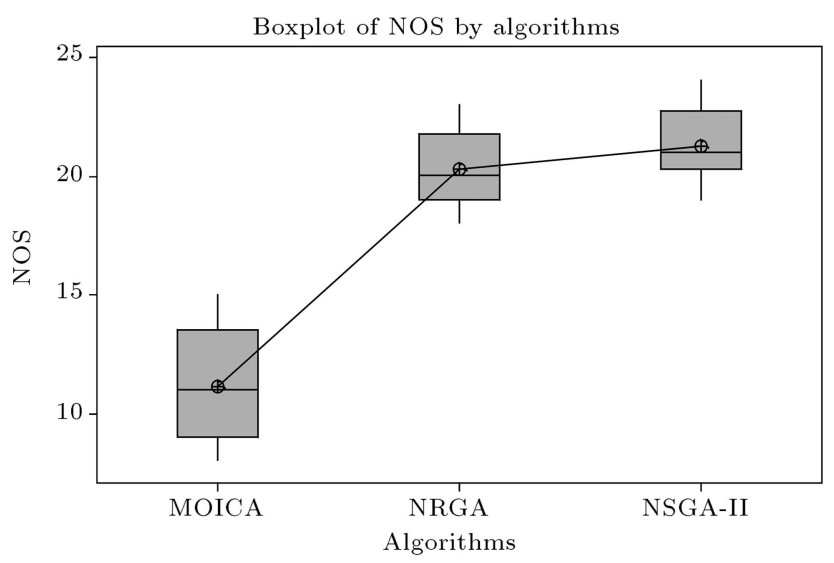

Figure 6. Box plot of NOS vs. algorithms.

terms of spacing, time, and MID metrics, in which the algorithms have no significant differences and statistically work the same; while MOICA is dominated by NRGA and NSGA-II in terms of NOS. It should be mentioned that these conclusions are confirmed with a confidence level of $95 \%$. Graphical outputs in Figure 8 


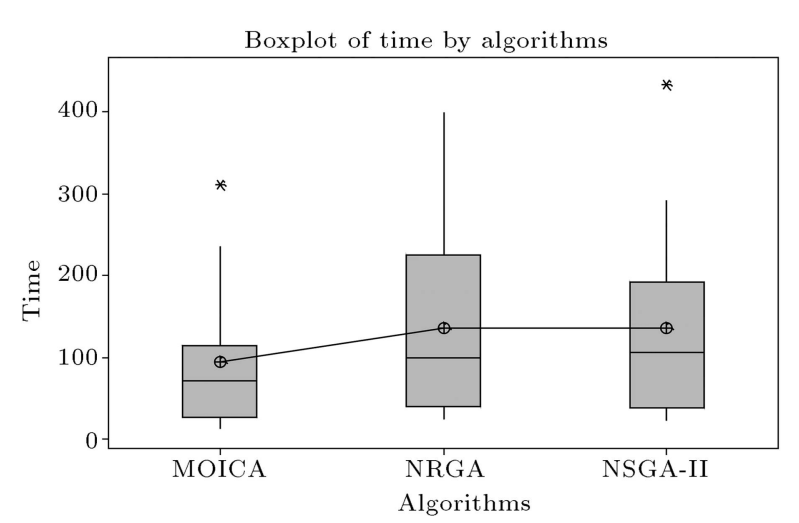

Figure 7. Box plot of time vs. algorithms.
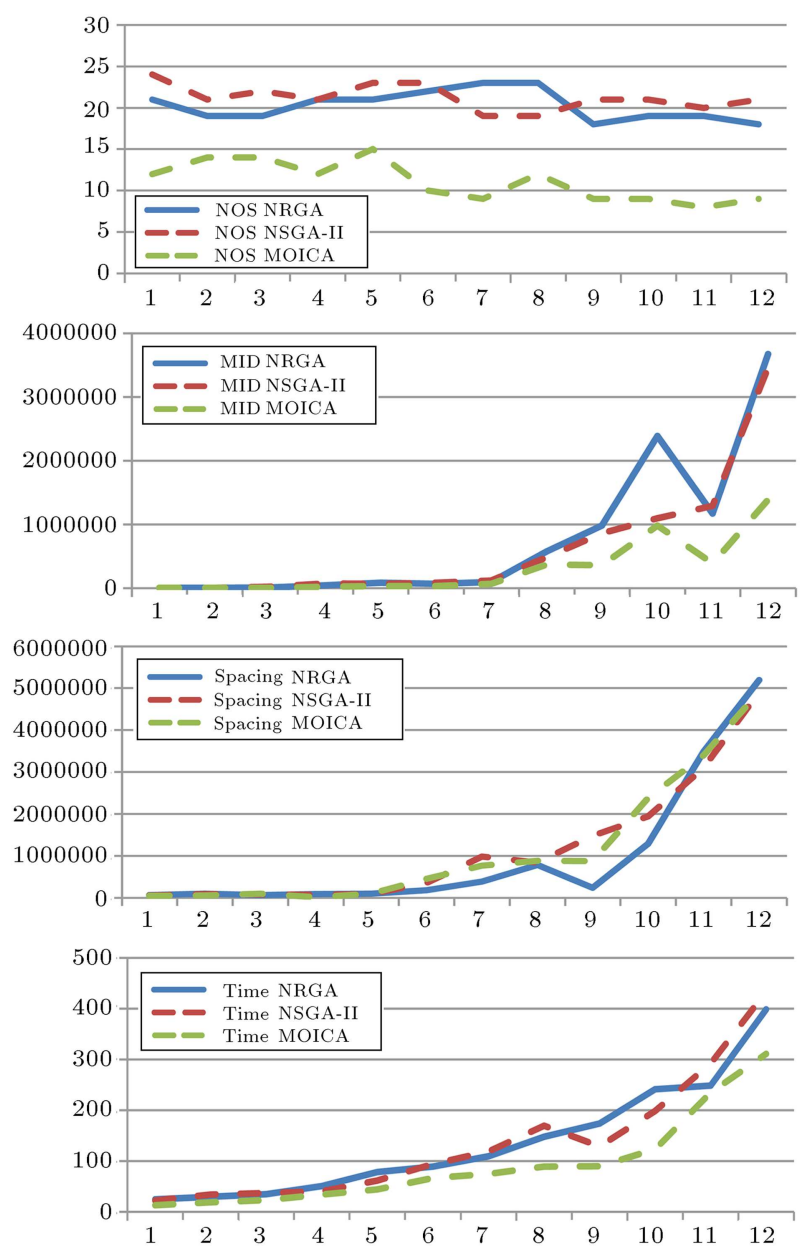

Figure 8. Graphical comparison of algorithms.

show better performance of MOICA in both MID and Time metrics.

\section{Conclusion}

In this paper, a bi-objective mathematical programming model is formulated to optimize supply chain network with location-inventory decisions for perishable items. Two objective functions, i.e. minimizing whole cost of the system and demand unresponsiveness, are met. With regard to complexity of the proposed model, a Pareto-based MOICA is presented to solve the model. Analysis of the results shows that the comparability of MOICA in comparison with NRGA and NSGAII in terms of spacing, time, and MID metrics. In Graphical comparison, MOICA has better performance on CPU time and MID metrics. For future research, one can design this supply chain network with forward and backward loops with environmental considerations.

\section{References}

1. Sabri, E. and Beamon, B. "A multi-objective approach to simultaneous strategic and operational planning in supply chain design", The International Journal of Management Science, 28(5), pp. 581-598 (2000).

2. Terzi, S. and Cavalieri, S. "Simulation in the supply chain context: A survey", Computers in Industry, 53(1), pp. 3-16 (2004).

3. Emmons, H. "A replenishment model for radioactive nuclide generators", Management Science, 14(5), pp. 263-274 (1968).

4. Shah, Y.K. and Jaiswal, M.C. "A periodic review inventory model for items that deteriorate continuously in time", International Journal of Production Research, 15(2), pp. 179-190 (1977).

5. Dave, U. "A probabilistic scheduling period inventory model for deteriorating items with lead times", Zeitschrift für Operations Research, 30(5), pp. A229A 237 (1986).

6. Naddor, R., Inventory Systems, New York, John Wiley and Sons (1966).

7. Prastacos, G.P. "Blood inventory management: An overview of theory and practice", Management Science, 30(7), pp. 777-800 (1984).

8. Brodheim, E. and Prastacos, G.P. "The long island blood distribution system as a prototype for regional blood management", Interfaces, 9(5), pp. 3-20 (1979).

9. Hemmelmayr, V., Doerner, K.F., Hartl, R.F. and Savelsbergh, M.W.P. "Delivery strategies for blood products supplies, Tech. Rep. 4, Department of Business Administration", University of Vienna and The Logistics Institute, Georgia Institute of Technology, Atlanta GA, (2009).

10. Goyal, S. and Giri, B. "Recent trends in modeling of deteriorating inventory", European Journal of Operational Research, 134(1), pp. 1-16 (2001).

11. Belien, J. and Forcé, H. "Supply chain management of blood products: A literature review", European Journal of Operational Research, 217(1), pp. 1-16 (2012).

12. European Medicines Agency, Guidelines on influenza vaccines prepared from viruses with the potential to cause a pandemic and intended for use outside of the core dossier context, London: EMEA, 24 Jan (2007). 
13. Carter, C.R. and Rogers, D.S. "A framework of sustainable supply chain management: moving toward new theory", International Journal of Physical Distribution \& Logistics Management, 38(5), pp. 360-387 (2008).

14. Nagurney, A. and Yu, M. "Sustainable fashion supply chain management under oligopolistic competition and brand differentiation", International Journal of Production Economics, 135(2), pp. 532-540 (2011).

15. Büyüközkan, G. and Berkol, I. "Designing a sustainable supply chain using an integrated analytic network process and goal programming approach in quality function deployment", Expert Systems with Applications, 38(11), pp. 13731-13748 (2011).

16. Chaabane, A., Ramudhin, A. and Paquet, M. "Design of sustainable supply chains under the emission trading scheme", International Journal of Production Economics, 135(1), pp. 37-49 (2012).

17. Erol, I., Sencer, S. and Sari, R. "A new fuzzy multicriteria framework for measuring sustainability performance of a supply chain", Ecological Economics, 70(6), pp. 1088-1100 (2011).

18. Wang, F., Lai, X. and Shi, N. "A multi-objective optimization for green supply chain network design", Decision Support Systems, 51(2), pp. 262-269 (2011).

19. Akkerman, R., Farahani, P. and Grunow, M. "Quality, safety and sustainability in food distribution: a review of quantitative operations management approaches and challenges", OR spectrum, 32(4), pp. 863-904 (2010).

20. Govindan, K., Maridossb, D., Jafarian, A. and Khodaverdi, R. "Two-echelon multiple-vehicle locationrouting problem with time windows for optimization of sustainable supply chain network of perishable food", Int. J. Production Economics, 152, pp. 9-28 (2014).

21. Katsaliaki, K., Mustafee, N. and Kumar, S. "A gamebased approach towards facilitating decision making for perishable products: An example of blood supply chain", Expert Systems with Applications, 41(9), pp. 4043-4059 (2014).

22. Duan, Q. and Liao, T.W. "Optimization of blood supply chain with shortened shelf lives and ABO compatibility", International Journal of Production Economics, 153, pp. 113-129 (2014).

23. Kalaitzidou, M.A., Longinidis, P. and Georgiadis, M.C. "Optimal design of closed-loop supply chain networks with malefunctional nodes", Computers \& Chemical Engineering, 80(2), pp. 73-91 (2015).

24. Fattahi, M., Mahootchi, M., Govindan, K. and Husseini, S.M.M. "Dynamic supply chain network design with capacity planning and multi-period pricing", Transportation Research Part E: Logistics and Transportation Review, 81, pp. 169-202 (2015).

25. Mousazadeh, M., Torabi, S.A. and Zahiri, B. "A robust possibilistic programming approach for pharmaceutical supply chain network design", Computers \& Chemical Engineering, 82, pp. 115-128 (2015).
26. Govindan, K., Jafarian, A. and Nourbakhsh, V. "Biobjective integrating sustainable order allocation and sustainable supply chain network strategic design with stochastic demand using a novel robust hybrid multiobjective metaheuristic", Computers \& Operations Research, 62, pp. 112-130 (2015).

27. Sharifzadeh, M., Garcia, M.C. and Shah, N. "Supply chain network design and operation: Systematic decision-making for centralized, distributed, and mobile biofuel production using mixed integer linear programming (MILP) under uncertainty", Biomass and Bioenergy, 81, pp. 401-414 (2015).

28. Ahn, Y.C., Lee, I.B., Lee, K.H. and Han, J.H. "Strategic planning design of microalgae biomass-tobiodiesel supply chain network: Multi-period deterministic model", Applied Energy, 154, pp. 528-542 (2015).

29. Pop, P.C., Pintea, C.M., Sitar, C.P. and HajduMacelaru, M. "An efficient reverse distribution system for solving sustainable supply chain network design problem", Journal of Applied Logic, 13(2), pp. 105$113(2015)$.

30. Yolmeh, A. and Salehi, N. "An outer approximation method for an integration of supply chain network designing and assembly line balancing under uncertainty", Computers \& Industrial Engineering, 83, pp. 297-306 (2015).

31. Deb, K., Pratap, A., Agarwal, S. and Meyarivan, T. "A fast elitist multi-objective genetic algorithm: NSGAII", IEEE Transactions on Evolutionary Computation, 6(2), pp. 182-197 (2002).

32. Bhattacharya, R. and Bandyopadhyay, S. "Solving conflicting bi-objective facility location problem by NSGA-II evolutionary algorithm", The International Journal of Advanced Manufacturing Technology, 51, pp. 397-414 (2010).

33. Hajipour, V., Khodakarami, V. and Tavana, M. "The redundancy queuing-location-allocation problem: A novel approach", IEEE Transactions on Engineering Management, 61(3), pp. 534-544 (2014).

34. Atashpaz-Gargari, E. and Lucas, C. "Imperialist competitive algorithm: an algorithm for optimization inspired by imperialist competition", IEEE Congress on Evolutionary Computation, CEC (2007).

35. Yang, G.Q., Liu, Y.K. and Yang, K. "Multi-objective biogeography-based optimization for supply chain network design under uncertainty", Computers \& Industrial Engineering, 85, pp. 145-156 (2015).

36. Rahmati, S., Hajipour, V. and Niaki, S. "A softcomputing Pareto-based meta-heuristic algorithm for a multi-objective multi-server facility location problem", Applied Soft Computing, 13(4), pp. 1728-1740 (2013). 
37. Yeniay, O. and Ankare, B. "Penalty function methods for constrained optimization with genetic algorithms", Mathematical and Computational Application, 10, pp. 45-56 (2005).

38. Enayatifar, R., Yousefi, M., Abdullah, A.H. and Darus, A.N. "MOICA: A novel multi-objective approach based on imperialist competitive algorithm", Applied Mathematics and Computation, 219(17), pp. 8829-8841 (2013).

39. Srinivas, N. and Deb, K. "Multiobjective function optimization using nondominated sorting genetic algorithms", Evol. Comput, 2(3), pp. 221-248 (1995).

40. Hajabdollahi, F., Hajabdollahi, Z. and Hajabdollahi, H. "Soft computing based multi-objective optimization of steam cycle power plant using NSGA-II and ANN", Applied Soft Computing, 12(11), pp. 3648-3655 (2012).

41. Haupt, R.L. and Haupt, S.E., Practical Genetic Algorithms, 2nd Ed., John Wiley \& Sons (2004).

42. Zitzler, E. and Thiele, L. "Multi-objective optimization using evolutionary algorithms a comparative case study", In A.E. Eiben, T. Back, M. Schoenauer and H.P. Schwefel (Eds.), Fifth International Conference on Parallel Problem Solving from Nature (PPSN-V), Berlin, Germany, pp. 292-301 (1998).

43. Zitzler, E. "Evolutionary algorithms for multiobjective optimization: method and applications", Ph.D Thesis, dissertation ETH NO. 13398, Swaziland Federal Institute of Technology Zorikh, Switzerland, 1999).

44. MATLAB Version 7.10.0.499 (R2010a), The MathWorks, Inc. Protected by U.S. and international patents (2010).

\section{Biographies}

Sadra Rashidi is PhD Student in the Department of Industrial Engineering at Islamic Azad University, Science and Research Branch, Tehran. He holds an $\mathrm{MSc}$ degree in Industrial Engineering from Islamic Azad University, Arak Branch, since 2010. His research interests are in the areas of supply chain management and DEA.

Abbas Saghaei is an Associate Professor in Industrial Engineering Department at Islamic Azad University, Science and Research branch. He received his $\mathrm{PhD}$ in Industrial Engineering from Iran University of Science and Technology. He holds a BSc and an MSc in Industrial Engineering. His research interests include quality engineering, and statistical learning and optimization. He is a board member of the Iranian Quality Management Society and a senior member of the American Society for Quality.

Seyed Jafar Sadjadi finished his $\mathrm{PhD}$ at the University of Waterloo, Canada. His research interest in focused on solving different classes of optimization problems in industrial engineering areas, such as supply chain management, portfolio optimization, optimal pricing, etc. He has been serving at Iran University of Science and Technology since 2001.

Soheil Sadi-Nezhad received his $\mathrm{PhD}$ in Industrial Engineering from the Islamic Azad University, Sciences \& Research Branch, in 1999. He has been working as a Post-Doctoral Fellow at Waterloo University. He used to be a Faculty Member at Islamic Azad University, Sciences \& Research Branch, and Industrial Management Institute of Iran. Most of his recent studies focus on mathematical modeling; decision-making; and multi-objective optimization under uncertainty, imprecision, and partial truth, especially as it involves human perceptions or risk. 